Acknowledgments: We thank the Coordination for the Improvement of Higher Level Personnel (Coordenação de Aperfeiçoamento de Pessoal de Nível Superior-CAPES) institution, the Foundation for Research Support of the Rio Grande do Sul State (Fundação de Amparo à Pesquisa do Estado do Rio Grande do Sul-FAPERGS), the Research and Events Incentive Fund (Fundo de Incentivo à Pesquisa e Eventos-FIPE) of HCPA and Technological Development (Conselho Nacional de Desenvolvimento Científico e Tecnológico-CNPq).

Disclosure of Interests: Rafaela Cavalheiro do Espírito Santo: None declared, Leonardo Santos: None declared, Lidiane Filippin: None declared, Priscila Lora: None declared, Ricardo Xavier Consultant of:AbbVie, Pfizer, Novartis, Janssen, Eli Lilly, Roche DOI: 10.1136/annrheumdis-2020-eular.2870

\section{THU0611-HPR MEASUREMENT OF MINIMAL DISEASE ACTIVITY IN PSORIATIC ARTHRITIS USING PROMIS-PHYSICAL FUNCTION OR THE HEALTH ASSESSMENT QUESTIONNAIRE-DISABILITY INDEX}

E. Chew ${ }^{1}$, J. Perin ${ }^{2}$, T. Grader-Beck', A. M. Orbai ${ }^{1} .{ }^{1}$ Johns Hopkins Hospital, Rheumatology, Baltimore, United States of America; ${ }^{2}$ Johns Hopkins University School of Public Health, Baltimore, United States of America

Background: Minimal disease activity (MDA) is a treat-to-target strategy (T2T) objective in psoriatic arthritis (PSA). MDA criteria, include physical function, traditionally assessed via the Health-Assessment Questionnaire Disability Index (HAQ-DI). It is of interest to assess the performance of more current physical function instruments such as the Patient-Reported Outcomes Measurement Information System-Physical Function Profile (PROMIS-PF).

Objectives: To assess the interchangeability of the HAQ-DI with the PROMIS-PF in the calculation of MDA in PsA.

Methods: Longitudinal PsA data were collected including HAQ-DI and PROMIS-PF in a PsA cohort. MDA definitions were built substituting the HAQ-DI criterion with the PROMIS-PF short form 4a (PROMIS-PF4a) or with the PROMIS-PF computer adaptive test (PROMIS-PF Bank). We assessed agreement/accuracy between HAQ-DI based and PROMIS-PF based MDA definitions at each visit and longitudinally through the kappa statistic/ROC curve analysis. Results: One hundred participants contributed 352 observations with up to five visits. Mean (SD) age was 52 (12) years, $60 \%$ were female, and $43 \%$ were in MDA at baseline. Kappa statistic for PROMIS-PF based MDA reflected almost perfect agreement with HAQ-DI MDA: kappa=0.94 (95\% Cl 0.90-0.97) for MDA PROMIS-PF Bank, and kappa $=0.90$ ( $95 \% \mathrm{Cl} 0.80-0.95)$ for MDA PROMISPF4a. Higher longitudinal agreement was seen between MDA HAQ-DI and MDA PROMIS-PF Bank versus MDA PROMIS-PF4a between consecutive visits:

Table 1. Agreement between HAQ-DI based MDA and PROMIS-PF based MDA definitions at each visit and longitudinally

\begin{tabular}{|c|c|c|c|c|c|}
\hline Agreement & & Visit 1 & Visit 2 & Visit 3 & Visit 4 \\
\hline MDA HAQ-DI and & Kappa & 0.91 & 0.93 & 0.92 & 0.83 \\
\hline \multirow[t]{2}{*}{ MDA PROMIS-PF4a } & $95 \% \mathrm{Cl}$ & $(0.80-0.98)$ & $(0.82-1.00)$ & $(0.80-1.00)($ & $(0.66-0.96)$ \\
\hline & $\mathrm{N}$ & 86 & 81 & 72 & 58 \\
\hline MDA HAQ-DI and & Kappa & 0.91 & 0.98 & 0.94 & 0.93 \\
\hline \multirow[t]{2}{*}{ MDA PROMIS-PF4a } & $95 \% \mathrm{Cl}$ & $(0.81-0.98)$ & $(0.90-1.00)$ & $(0.84-1.00)($ & $(0.82-1.00)$ \\
\hline & $\mathrm{N}$ & 86 & 82 & 73 & 58 \\
\hline Longitudinal agreement & & $\begin{array}{l}\text { Visit } 1 \text { to } \\
\text { visit } 2\end{array}$ & $\begin{array}{l}\text { Visit } 2 \text { to } \\
\text { visit } 3\end{array}$ & $\begin{array}{c}\text { Visit } 3 \text { to } \\
\text { visit } 4\end{array}$ & $N / A$ \\
\hline MDA HAQ-DI state change with & Kappa & 0.75 & 0.84 & 0.72 & N/A \\
\hline \multirow[t]{2}{*}{ MDA PROMIS-PF4a state change } & $95 \% \mathrm{Cl}$ & $(0.47-0.95)$ & $(0.58-1.00)$ & $(0.37-0.94)$ & \\
\hline & $\mathrm{N}$ & 71 & 67 & 51 & \\
\hline MDA HAQ-DI state change with MDA & Kappa & 0.81 & 0.94 & 0.84 & N/A \\
\hline \multirow[t]{2}{*}{ PROMIS-PF Bank state change } & $95 \% \mathrm{Cl}$ & $(0.49-1.00)$ & $(0.75-1.00)$ & $(0.48-1.00)$ & \\
\hline & $\mathrm{N}$ & 72 & 68 & 52 & \\
\hline
\end{tabular}

${ }^{*}$ Bias corrected $95 \% \mathrm{Cl}$ were calculated using bootstrapping with 2000 repetitions of individual patients.

MMDA state changes are defined as transitions in the respective MDA state between designated consecutive visits

Abbreviations: $\mathrm{Cl}$ confidence interval; $\mathrm{N}$ number of observations; HAQ-DI Heath Assessment Questionnaire-Disability Index; PROMIS-PF4a Patient Reported Outcomes Measurement Information System Physical Function form 4a; PROMIS-PF Bank Patient Reported Outcomes Measurement Information System Physical Function Bank administered as a computer adaptive test; MDA HAQ-DI Minimal disease activity includes the HAQ-DI $\leq 0.5$ criterion; MDA PROMIS-PF4a includes the PROMIS-PF4a $\geq 41.3$ criterion; MDA PROMIS-PF Bank includes the PROMIS-PF CAT $\geq 41.3$ criterion kappa ranged between 0.81-0.94 versus 0.72-0.84, respectively (Table 1). Area under ROC curve for predicting MDA HAQ-DI was 0.97 for MDA PROMIS-PF Bank and 0.95 for MDA PROMIS-PF4a (Figure 1).
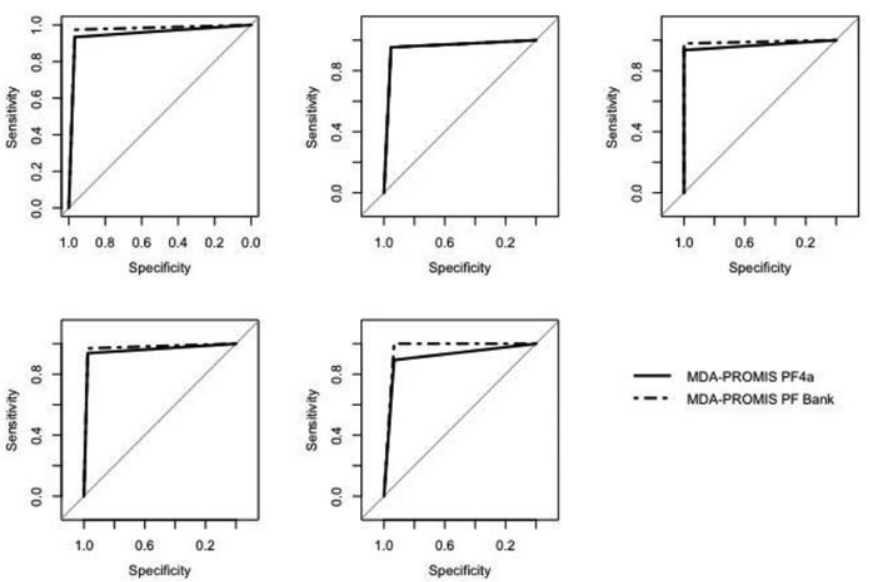

Figure 1. Areas under receiver operative characteristic curve to predict $H A Q-D I$ based MDA using MDA PROMIS-PF4a or MDA PROMIS-PF Bank at each visit and overall using all observations (from left to right: visit 1, 2, 3, 4, and overall across visits)

Conclusion: Excellent agreement was seen between HAQ-DI and PROMISbased MDA definitions statically and longitudinally. The PROMIS-PF Bank and PROMIS-PF4a are accurate replacements for the HAQ-DI in calculating MDA state in PsA.

References:

[1] Schalet BD, et al. J Gen Intern Med 2015

Disclosure of Interests: Erin Chew: None declared, Jamie Perin: None declared, Thomas Grader-Beck Grant/research support from: Abbvie, Celgene, Consultant of: Novartis, Lilly, Ana-Maria Orbai Grant/research support from: Abbvie, Eli Lilly and Company, Celgene, Novartis, Janssen, Horizon, Consultant of: Eli Lilly; Janssen; Novartis; Pfizer; UCB. Ana-Maria Orbai was a private consultant or advisor for Sun Pharmaceutical Industries, Inc, not in her capacity as a Johns Hopkins faculty member and was not compensated for this service.

DOI: 10.1136/annrheumdis-2020-eular.212

\section{THU0612-HPR DOES PAIN AND COMORBIDITY BURDEN PREDICT FRAILTY IN PATIENTS WITH KNEE-OSTEOARTHRITIS? FINDINGS FROM THE RESEARCH ON OSTEOARTHRITIS AGAINST FRAILTY (ROAF) STUDY.}

F. Salaffi ${ }^{1}$, M. Carotti ${ }^{2}$, S. Farah ${ }^{1}$, M. DI Carlo ${ }^{1}$, A. Giovagnoni ${ }^{2},{ }^{1}$ Hospital "Carlo Urbani", Università Politecnica delle Marche, Scienze Cliniche e Molecolari, Jesi, Italy; ${ }^{2}$ Ospedali Riuniti Torrette Di Ancona, Radiologia, Torrette, Ancona, Italy

Background: Pain and comorbidity burden has been suggested to act as a stressor during aging, potentially accelerating declines in health and functioning in patients with osteoarthritis of the knee (KNEE-OA) $(1,2)$.

Objectives: The aims of the present research were to assess (i) the prevalence of frailty and (ii) its potential associated factors in a cohort of adult patients with KNEE-OA.

Methods: Patients fulfilling the clinical American College of Rheumatology knee-OA criteria were assessed according to the Survey of Health, Ageing and Retirement in Europe Frailty Instrument (SHARE-FI), and classified as frail, prefrail, or non-frail. The clinical evaluation included the following items: Western Ontario and McMaster Universities Osteoarthritis Index (WOMAC) Pain subscale (3) and Medical Outcomes Study Short Form-36 (SF-36). Evaluation of the comorbidities burden was performed with the modified Rheumatic Disease Comorbidity Index (mRDCl). Radiographic knee OA was defined according to Kellgren/Lawrence (KL) grades. Chi-square, analysis of variance (ANOVA), and multinomial logistic regression analyses were used to test the prognostic value of frailty for the outcomes of interest. 
Table 1. Multinomial logistic regression analyses:c oefficients, standard errors and Wald statistic.

\begin{tabular}{lcccc}
\hline Variable & Coefficient & Std. Error & Wald & P \\
\hline Age, yrs & -0.17872 & 0.065399 & 4.4682 & 0.0534 \\
Gender & -0.087304 & 0.73366 & 0.01416 & 0.9053 \\
BMI, Kg/m & -0.096320 & 0.081124 & 1.4097 & 0.2351 \\
Pain duration from diagnosis, yrs & 0.13065 & 0.069051 & 3.5801 & 0.0585 \\
Educational level, yrs & 0.066913 & 0.080301 & 0.6944 & 0.4047 \\
Kellgren/Lawrence grades & 0.62074 & 0.50629 & 1.5032 & 0.2202 \\
mRDCl & -0.60277 & 0.18993 & 10.0714 & 0.0015 \\
SF36-MCS & 0.028143 & 0.020074 & 1.9655 & 0.1609 \\
SF36-PCS & -0.00070260 & 0.025118 & 0.0007824 & 0.9777 \\
WOMAC Pain subscale & -0.29129 & 0.081619 & 12.7373 & 0.0004 \\
Constant & 17.42518 & 5.73269 & 9.2393 & 0.0024 \\
\hline
\end{tabular}

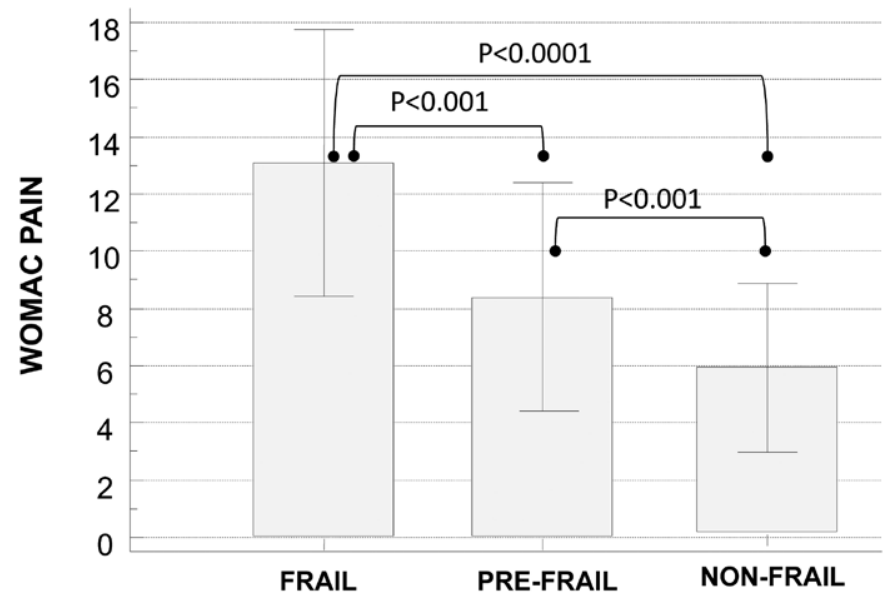

Figure 1. Distribution of the WOMAC-Pain scores according to the frailty categories by SHARE-FI, and p-values for comparison (ANOVA test)

Conclusion: Frailty or pre-frailty are common in KNEE-OA. The main factors associated with frailty were pain and comorbidity burden. Implementation of the frailty assessment into the routine rheumatological practice could represent a major advance in KNEE-OA care. Further studies are needed to identify the physiological mechanisms underpinning these associations.

References:

[1] Veronese N, Maggi S, Trevisan C, Noale M, De Rui M, Bolzetta F, Zambon S, Musacchio E, Sartori L, Perissinotto E, Stubbs B, Crepaldi G, Manzato E, Sergi G. Pain Increases the Risk of Developing Frailty in Older Adults with Osteoarthritis. Pain Med. 2017;18(3):414-427.

[2] Salaffi F, Carotti M, Grassi W. Health-related quality of life in patients with hip or knee osteoarthritis: comparison of generic and disease-specific instruments. Clin Rheumatol. 2005 Feb;24(1):29-37.

[3] Salaffi F, Leardini G, Canesi B, Mannoni A, Fioravanti A, Caporali R, Lapadula G, Punzi L; GOnorthrosis and Quality Of Life Assessment (GOQOLA). Reliability and validity of the Western Ontario and McMaster Universities (WOMAC) Osteoarthritis Index in Italian patients with osteoarthritis of the knee. Osteoarthritis Cartilage. 2003;11(8):551-60.

Disclosure of Interests: None declared

DOI: 10.1136/annrheumdis-2020-eular.3531

\section{THU0613-HPR ADAPTATION AND VALIDATION OF THE MINI OSTEOARTHRITIS KNEE AND HIP QUALITY OF LIFE (MINI-OAKHQOL) QUESTIONNAIRE IN TURKISH POPULATION}

M. T. Duruöz ${ }^{1}$, S. Acer Kasman ${ }^{1}$, H. H. Gezer ${ }^{1} .{ }^{1}$ Marmara University, School of Medicine, Physical Medicine and Rehabilitation Department, Rheumatology Division, Istanbul, Turkey

Background: The 20-item Mini-OAKHQOL was derived from the 40-item OAKHQOL questionnaire which was developed to assess the quality of life in subjects with osteoarthritis of the lower limbs. It has 5 subscales containing physical activities, mental health, pain, social support, social functioning; and two independent items addressing sex life and professional life (1). The Mini-OAKHQOL's good psychometric properties have recently been shown and validation studies have been done in several populations $(1,2)$.

Objectives: We aimed to investigate the validity and reliability of the Turkish version of the Mini-OAKHQOL in patients with knee and hip osteoarthritis.

Methods: Patients diagnosed with knee or hip osteoarthritis clinically and radiologically were included in the study. Demographic data were noted. The French version of Mini-OAKHQOL was used for translation and adaptation. Translation-back translation methodology was applied and cross-cultural adaptation of the Mini-OAKHQOL into Turkish was done. Face and content validities were evaluated by cognitive information interviews with patients and expert committee. Internal consistency of the scale was made with Cronbach alpha coefficient Convergent validity was evaluated by the correlations of Mini-OAKHQOL with Nothingam Health Profile (NHP), subscales of Short form 36 (SF-36), and VAS of the quality of life. The relations of the Mini-OAKHQOL with age, BMI, disease duration, VAS of the pain, WOMAC, and Lequesne Index were assessed for divergent validity. $P<0.05$ was considered significant.

Results: Seventy-three patients (63 female, 10 male) with the mean age of 57.22 (SD: 9.91) years were recruited. The main site of the symptomatic lower limb osteoarthritis was knee in 44 , hip in 25 , and both in 4 patients. The mean BMI was 31.69 (SD: 11.06) and the median disease duration was 36 months (IQR: 12-72). Turkish version of Mini- OAKHQOL had a good face and content validity. Cronbach's alpha coefficients of the subscales for internal consistency were $0.927,0.841,0.867,0.771$, and 0.677 . Physical activities, mental health, pain dimensions of Mini-OAKHQOL had moderate to high correlations with Nottingham Health Profile and the physical functioning, physical role limitations, energy/fatigue, social functioning, pain, and general health subscales of SF-36 (rho between 0.484-0.748). The social function subscale of Mini-OAKHQOL had mild significant correlations with emotional well-being (rho: 0.239) and general health (rho: 0.315) subscales of SF36. The subscales of Mini-OAKHQOL had no correlation with disease duration, BMI, and age; and had generally moderate correlations with VAS-pain, Lequesne Index, and the WOMAC subscales. These data show good convergent and divergent validities of Mini-OAKHQOL.

Conclusion: The Turkish version of the Mini-OAKHQOL is a valid and reliable instrument to assess the quality of life in patients with knee/hip osteoarthritis In addition, it is a simple, accurate, disease-specific, and not time-consuming self-report instrument.

\section{References:}

[1] Guillemin F, Rat AC, Goetz C, Spitz E, Pouchot J, Coste J. The Mini-OAKH QOL for knee and hip osteoarthritis quality of life was obtained following recent shortening guidelines. J Clin Epidemiol. 2016;

[2] Gonzalez Sáenz de Tejada M, Bilbao A, Herrera C, García L, Sarasqueta C, Escobar A. Validation of the Mini-OAKHQOL for use in patients with osteoarthritis in Spain. Clin Rheumatol. 2017;

Disclosure of Interests: None declared

DOI: 10.1136/annrheumdis-2020-eular.3976

\section{THU0614-HPR ASSESSING THE EFFECT OF INTERVENTIONS FOR AXIAL SPONDYLOARTHRITIS ACCORDING TO THE ENDORSED ASAS/OMERACT CORE OUTCOME SET: A META-RESEARCH STUDY OF TRIALS INCLUDED IN COCHRANE REVIEWS}

R. Asmussen Andreasen ${ }^{1,2}$, L. E. Kristensen ${ }^{3}, X$. Baraliakos ${ }^{4}$, V. Strand ${ }^{5}$, P. J. Mease ${ }^{6}$, M. De Wit ${ }^{7}$, T. Ellingsen ${ }^{8}$, I. M. Jensen Hansen ${ }^{1}$, J. Kirkham ${ }^{9}$, G. Wells ${ }^{10}$, P. Tugwell ${ }^{11}$, L. Maxwell ${ }^{11}$, M. Boers ${ }^{12}$, K. Egstrup $^{13}$, R. Christensen ${ }^{2,8} .{ }^{1}$ Odense University Hospital, Svendborg, Medicine, Section of Rheumatology, Svendborg, Denmark; ${ }^{2}$ Musculoskeletal Statistics Unit, the Parker Institute, Bispebjerg and Frederiksberg Hospital, Copenhagen F, Denmark. University Hospital, Denmark, Copenhagen, Denmark; ${ }^{3}$ Musculoskeletal Statistics Unit, the Parker Institute, Bispebjerg and Frederiksberg Hospital, Copenhagen F, Denmark. University Hospital, Denmark, Muculoskeletal Statistics Unit, Copenhagen, Denmark

${ }^{4}$ Rheumazentrum Ruhrgebiet Herne, Ruhr-University Bochum, Germany, Herne, Germany; ${ }^{5}$ Division Immunology/Rheumatology, Stanford University, Palo Alto, California, USA., Palo Alto, United States of America; ${ }^{6}$ Swedish Medical Centre/ Providence St. Joseph Health and University of Washington, Seattle, USA., Seattle, United States of America; ${ }^{7}$ VU University Medical Centre, Department of Medical Humanities, Amsterdam, the Netherlands, Amsterdam, Netherlands; ${ }^{8}$ Research Unit of Rheumatology, Department of Clinical Research, University of Southern Denmark, Odense University Hospital, Denmark, Odense, Denmark; ${ }^{9}$ Centre for Biostatistics, Manchester Academic Health Science, United Kingdom, Manchester, United Kingdom;

${ }^{10}$ Department of Medicine, University of Ottawa, Ottawa, Ontario, Canada, Ontario, Canada; ${ }^{11}$ Faculty of Medicine, University of Ottawa, Ottawa, Ontario, 